SANDIA REPORT

SAND97-2332 • UC-701

Unlimited Release

+ Printed September 1997

DEC 151997

OSTI

\title{
Method for Measuring Deuterium in Erbium Deuteride Films
}

DSTRIBUTON OF THIS DOCURENT is UNMUITED oh

James R. Brangan, Steven M. Thornberg, M. R. Keenan

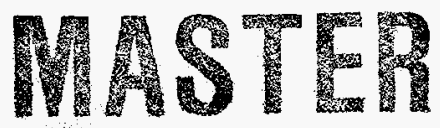

Prepared by

Sandia National Laboratories

Albuquerque, New Mexico 87185 and Livermore, California 94550

Sandia is a multiprogram laboratory operated by Sandia Corporation,

a Lockheed Martin Company, for the United States Department of

Energy under Contract DE-AC04-94AL85000.

Approved for public release; further dissemination unlimited.

\section{iit Sandia National Laboratories}


Issued by Sandia National Laboratories, operated for the United States Department of linergy by Sandia Corporation.

NOTICE: This report was prepared as an account of work sponsored by an agency of the United States Government. Neither the United States Government nor any e.gency thereof, nor any of their ernployees, nor any of their contractors, subcontractors, or their employees, makes any warranty, express or implied, or assumes any legal liability or responsibility for the accuracy, completeness, or usefulness of any information, apparatus, product, or process disclosed, or represents that its use would not infringe privately owned rights. Reference herein to any specific commercial product, process, or service by trade name, trademark, manufacturer, or otherwise, does not necessarily constitute or imply its endorsement, recommendation, or favoring by tie United States Government, any agency thereof, or any of their contractors or subcontractors. The views and opinions expressed herein do not $n \in$ cessarily state or reflect those of the United States Government, any agenc; thereof, or any of their contractors.

Printed in the United States of America. This report has been reproduced directly from the best available copy.

Available to DOE; and DOE contractors from

Office of Scientific and Technical Information

P.O. Box 62

Oak Ridge, TIN 37831

Prices available from (615) 576-8401, FTS 626-8401

Available to the Fublic from

National Technical Information Service

U.S. Departmınt of Commerce

5285 Port Roy al Rd

Springfield, VA 22161

NTIS price codes

Printed copy: A03

Microfiche copy: A01 


\section{DISCLAIVER}

Partions of this docoment mey be illegible in electronic imige products. Ingges are produced from the best availabile original coesment 
SAND97-2332

Distribution

Unlimited Release

Category UC-701

Printed September 1997

\title{
Method for Measuring Deuterium in Erbium Deuteride Films
}

\author{
James R. Brangan, Steven M. Thornberg, and M. R. Keenan \\ Analytical Chemistry Department \\ Sandia National Laboratories \\ P.O. Box 5800 \\ Albuquerque, New Mexico 87185-0343
}

\begin{abstract}
Determining the quantity of deuterium in an erbium deuteride $\left(\mathrm{ErD}_{2}\right)$ film is essential for assessing the quality of the hydriding process but is a challenging measurement to make. First, the ideal gas law cannot be applied directly due to high temperature $\left(950^{\circ} \mathrm{C}\right)$ and low temperature $\left(25^{\circ} \mathrm{C}\right)$ regions in the same manifold. Additionally, the metal hydride does not release all of the deuterium rapidly upon heating and metal evaporation occurs during extended heating periods. Therefore, the method developed must provide a means to compensate for temperature inhomogeneities and the amount of deuterium retained in the metal film while heating for a minimal duration. This paper presents two thermal desorption methods used to evaluate the kinetics and equilibria of the deuterium desorption process at high temperatures $\left(950^{\circ} \mathrm{C}\right)$. Of primary concern is the evaluation of the quantity of deuterium remaining in these films at the high temperature. A multiple volume expansion technique provided insight into the kinetics of the deuterium evolution and metal evaporation from the film. Finally a repeated pump-down approach yielded data that indicated approximately $10 \%$ of the deuterium is retained in the metal film at $950^{\circ} \mathrm{C}$ and approximately 1 Torr pressure. When the total moles of deuterium determined by this method were divided by the moles of erbium determined by ICP/AES, nearly stochiometric values of 2:1 were obtained for several erbium dideuteride films. Although this work presents data for erbium and deuterium, these methods are applicable to other metal hydrides as well.
\end{abstract}




\section{Acknowledgnients}

The authors wish to acknowledge Sharon Metzger for the experimental work in obtaining the gas evolution data. Appreciation also goes to Curt Mowry, Jim Browning, Tom Mehrhoff, Richard Kunhart, James L. Provo and Robert Koss for their useful insights into the gas retention and metal evaporation phenomenon, and to Bill Chambers and Jeanne Barrera for the ICP-AES metal analyses. 


\section{Contents}

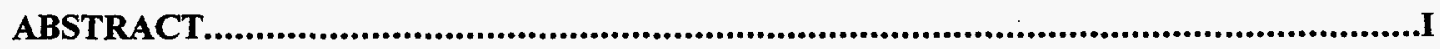

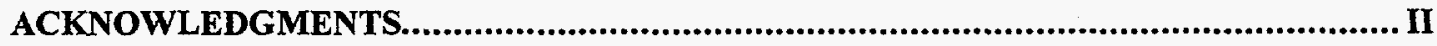

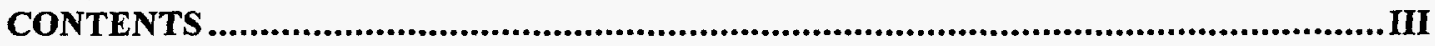

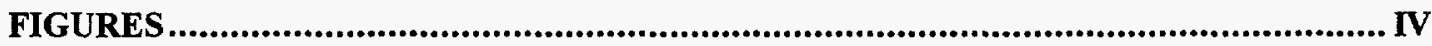

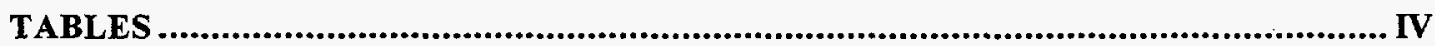

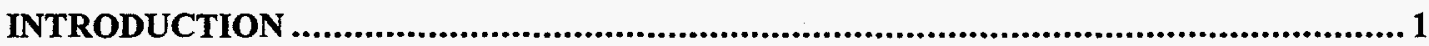

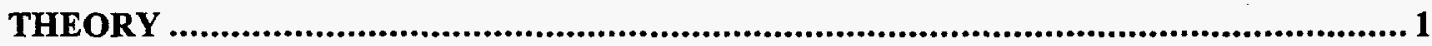

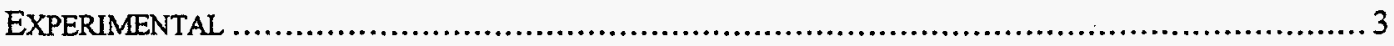

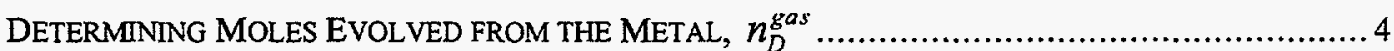

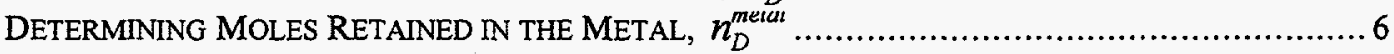

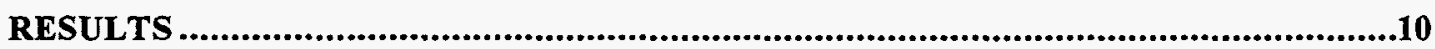

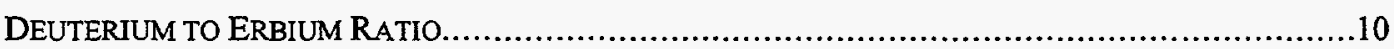

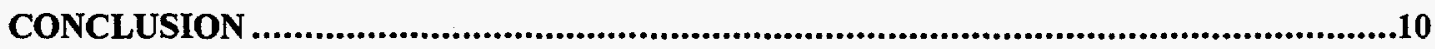

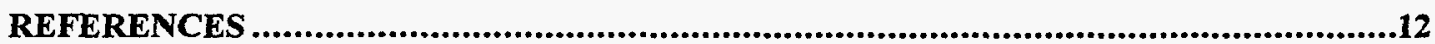

- iii - 


\section{Figures}

FIGURE 1. EXPERIMENTAL SETUP FOR THE HYDRIDE OUTGASSING EXPERIMENTS..... 3

FIGURE 2. MOLES OF GAS FROM AN ERBIUM DEUTERIDE FILM AS A FUNCTION OF INDICATED TEMPERATURE. 4

FIGURE 3. PLOT OF EFFISCTIVE TEMPERATURE (A) AND INDICATED TEMPERATURE (B) VERSUS TIME FOR THE STANDAFD DEUTERIUM FILL FOR INITIAL RAMP......................................

FIGURE 4. PLOT OF INDICATED TEMPERATURE (A) AND EFFECTIVE TEMPERATURE (B) VERSUS TIME FOR THE STANDARD DIJUTERIUM FILL FOR MULTIPLE VOLUME EXPANTION.......................... 6

FIGURE 5. PLOT OF MOLES OF GAS EVOL VED FROM AN ERBIUM DEUTERIDE SAMPLE VERSUS TIME.... 7 FIGURE 6. CUMULATIV $\Xi$ AMOUNT OF DEUTERIUM $\left(\mathrm{D}_{2}, \mathrm{HD}\right.$ AND TOTAL) REMOVED DURING THE PUMP DOWN PROCESS. AFTER ABOUT 7 RUNS VERY LITTLE DEUTERIUM REMAINED IN THE GAS PHASE AFTER COOLING.

\section{Tables}

TABLE 1. VALUES FOR THE CALIBRATED VOLUMES USED IN EXPERIMENTS 3

TABLE 2. EFFECTIVE TIIMPERATURE OF THE MANIFOLD AT AIND INDICATED TEMPERATURE OF $950^{\circ} \mathrm{C}$ $\left(1223^{\circ} \mathrm{K}\right)$

TABLE 3. RESULTS OF THE REPEATED VACUUM REMOVAL OF DEUTERIUM BETWEEN HEATING/COOLING CYCLES. THE DATA SHOWS ABOUT 10\% OF THE TOTAL MOLES OF GAS STORED IN THE METAL HYDRIDE WAS NOT MEASURED (RETAINED IN THE METAL HYDRIDE) AFTER THE FIRST R.UN .

TABLE 4. SUMMARY OF RESULTS OBTAINED FOR THE RATIO OF DEUTERIUM TO ERBIUM FOR A SERIES OF SAMPLES. 


\section{Method for Measuring Deuterium in Erbium Deuteride Films}

\section{Introduction}

Erbium films are used for the long term storage of hydrogen isotopes. These films are produced by evaporating erbium under vacuum and at elevated temperature onto molybdenum substrates. The pure erbium film is then loaded with deuterium gas for storage in the stable, dideuteride form. Present applications call for films from one to ten microns in thickness. As a dihydride, these films have a uniform "robin's egg" blue appearance. Despite this visual indication, it is very important to assure that the entire film is in the dideuteride form for long term stability. This paper outlines a procedure that can be used to verify this state.

In order to determine the quality of the hydride film, the quantities of erbium and deuterium must be accurately measured. The essential idea underlying the measurement process is to thermally desorb and measure the deuterium released from the film, followed by a wet chemical analysis to determine the erbium content. The erbium measurement is straightforward using inductively coupled argon plasma atomic emission spectroscopy (ICP/AES). The measurement of the deuterium is more difficult as it must be outgassed from the erbium at elevated temperatures without removing or damaging the erbium. This measurement is further complicated by the temperature and pressure dependence of the gas/solid equilibria in these films ${ }^{1-13}$, the kinetics of the desorption process $^{3,13}$ and experimental difficulties associated with making measurements at high temperatures.

This paper presents a method for determining the quantity of deuterium contained in an erbium deuteride film that is based on desorption of deuterium during a temperature ramp. Consideration is given to the kinetics of the deuterium outgassing, metal decomposition, and the gas/solid equilibrium. Also noted are the practical considerations that must be evaluated when performing this type of analysis.

\section{Theory}

The figure of merit for evaluating the quality of the erbium deuteride film is

$$
R=\frac{n_{D}}{n_{E r}}
$$

where $R$ is the ratio of the moles of deuterium atoms, $n_{D}$, to the moles of erbium atoms, $n_{E r}$. A ratio of 2 indicates complete dihydride formation. The moles of erbium atoms are determined by ICP/AES after the moles of deuterium atoms have been determined following high temperature desorption of the deuterium gas from the film.

Since gas/solid equilibrium causes some deuterium to be retained in the metal even at high temperatures, the total number of moles of deuterium atoms is the sum of the moles of deuterium atoms in the gas phase following desorption $n_{D}^{\text {gus }}$ and those retained in the erbium metal $n_{D}^{\text {meta }}$.

$$
n_{D}=n_{D}^{\text {gas }}+n_{D}^{\text {metal }}
$$


Quantitation of the desorbed deuterium will be described below and determination of the deuterium remaining in the metal will be discussed in a later section.

Given pure deuterium loading of the erbium film, gas phase deuterium can be found, in the desorption chamber, as both $\mathrm{D}_{2}$ and $\mathrm{HD}$ (protium-deuteride) due to protium/deuterium exchange reactions at high temperatures. The sources for protium include residual hydrogen outgassed from stainless steel walls and adsorbed water in the system. The moles of deuterium atoms can then be expressed in terms of the total moles of gas in the chamber, $n_{\text {total }}$ :

$$
n_{D}^{\text {gas }}=n_{\text {total }}\left(2 X_{D_{2}}+X_{H D}\right)
$$

where the mole fractions of $\mathrm{D}_{2}, X_{D_{2}}$, and $\mathrm{HD}, X_{H D}$ are determined from mass spectral analysis. The mole fraction for $D_{2}$ is multiplied by 2 since two deuterium atoms are obtained from each molecule of deuterium gas. Some deuterium atoms will also be lost from the gas phase to the surface of the manifold. However, the effect is assumed to be small and will be neglected. For the remainder of this paper, moles of deuterium will refer to moles of deuterium atoms, not molecules.

It would be desirable to be able to calculate the total moles of gas in the system by using the ideal gas equation:

$$
n_{\text {total }}=\frac{P V}{R T}
$$

where $P$ is the presisure of a gas and $V$ is the volume it occupies, $R$ is the ideal gas constant, and $T$ is the gas temperature. However, while pressure and volume are readily measured, temperature does not have a well defined meaning in the present experiment for several reasons. First, the only temperature reading is obtained from a thermocouple that is external to the sample tube, thus, while useful for controlling the furnace, it does not provide a value that can be directly inserted into the gas equation calculations. More fundamentally, the measurement system is not isothermal, with temperatures ranging from room temperature at the pressure gauge to nearly $1000^{\circ} \mathrm{C}$ at the sample tube, and thermal steady state is never achieved during the course of the experiment. However, if we make the assumption that the time-dependent temperature distribution within the measurement system will be reproducible for identical sets of experimental conditions (equipment configuration, $\mathrm{P}, \mathrm{V}$, temperature ramp rates, time-related parameterswitching profiles, etc.), then we can define an operational or effective system temperature $T_{\text {eff }}$ at any instant during the experimental run. This is accomplished by loading the chamber with a known quantity $n_{\text {std }}$ of nonreactive gas and observing its pressure $P_{\text {std }}$, as a function of time, when subjected to an identical experimental profile. $T_{\text {eff }}$ is then simply defined as that value of temperature that satisfies the ideal gas law for the given $\mathrm{n}, \mathrm{P}$ and $\mathrm{V}$ at time $t$ during the run:

$$
T_{e f f}(t) \equiv \frac{P_{s t: z}(t) V(t)}{n_{s t d} R}
$$

where the potential time dependencies are explicitly shown. Equation 5 is general and makes no assumptions about the functional relationships between the individual parameters and time. It can, for example, account for instantaneous changes in system volume as will be shown below for the multiple volume expansion method. For arbitrary experimental profiles, Eq. 5 is most conveniently described and evaluated through the use of lookup tables.

Substituting $T_{\text {eff }}$ for $T$ in Eq. 4 and combining with equations 2 and 3, yields the final expression for $n_{D}$ : 


$$
n_{D}=\frac{P V}{R T_{\text {eff }}}\left(2 X_{D}+X_{H D}\right)+n_{D}^{\text {metal }}
$$

\section{Experimental}

Figure 1 shows a schematic of the apparatus used to make these measurements. The sample, either pure $\mathrm{D}_{2}$ gas or the erbium deuteride sample, is introduced into the quartz tube. The volume the gas expands into is labeled $V_{1}$ and consists of the quartz tube, manifold, and the pressure gauge. An oven is placed around the quartz tube for heating the sample and the stainless steel manifold is heated to $150^{\circ} \mathrm{C} \pm 2^{\circ} \mathrm{C}$ using heating tape to minimize water adsorption. On the outside of the quartz tube is the feedback thermocouple used to measure the indicated temperature and provide temperature feedback to the oven controller. Additional volumes, $V_{2}$ and $V_{3}$ were installed on the system for the multiple volume expansion experiments described later. The value of each volume is shown in Table 1. Mole fraction measurements were made by directly introducing the gas from $V_{1}$ into a calibrated mass spectrometer and measuring the $\% \mathrm{D}_{2}$ and $\% \mathrm{HD}$.

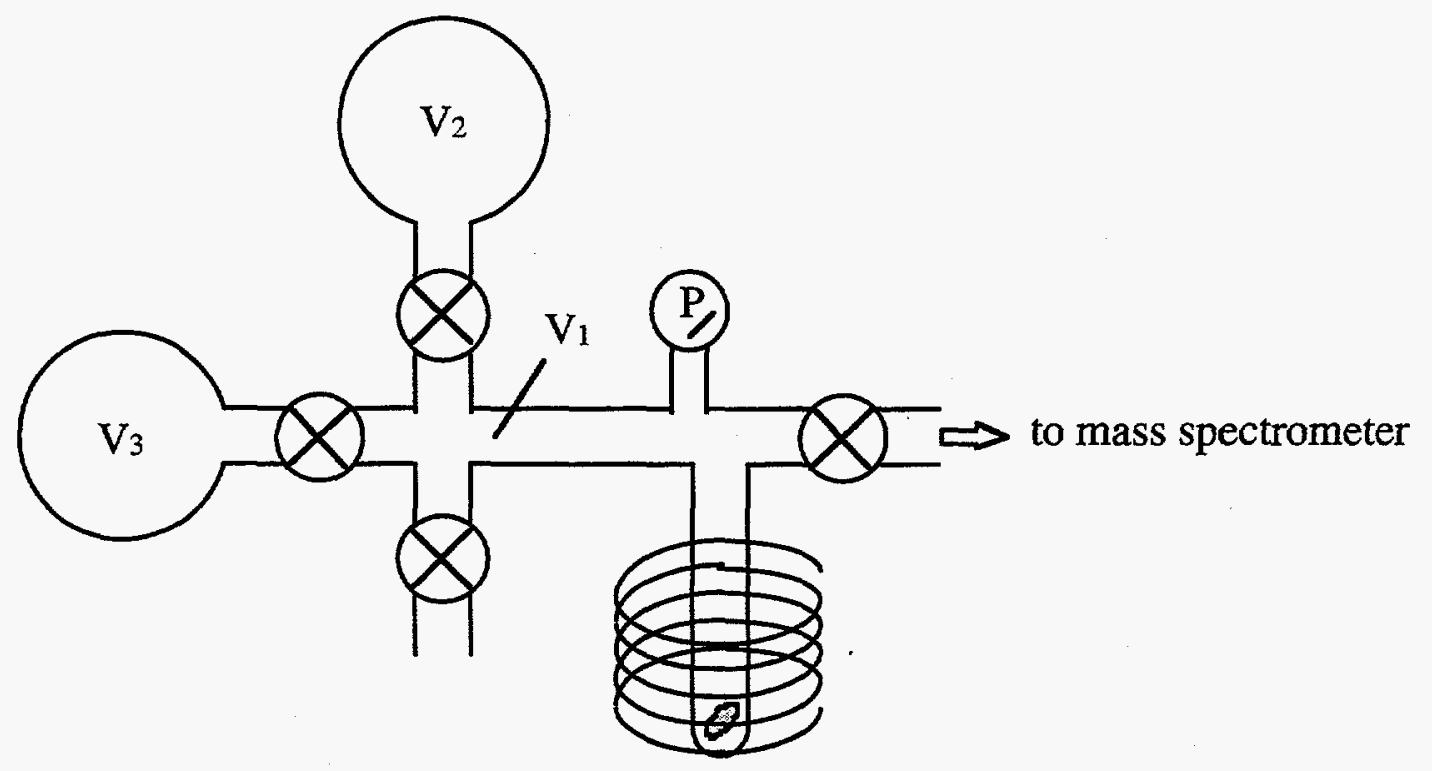

Figure 1. Experimental setup for the hydride outgassing experiments.

Table 1. Values for the calibrated volumes used in experiments.

\begin{tabular}{|c|c|}
\hline Volume & $\begin{array}{c}\text { Calibration Value } \\
\left(\mathbf{c m}^{\mathbf{3}}\right)\end{array}$ \\
\hline$V_{1}$ (Repeated Outgassing Experiment) & $396.0 \pm 2.6$ \\
$V_{1}$ (Multiple Volume Expansion) & $124.4 \pm 0.1$ \\
$V_{1}+V_{2}$ & $424.4 \pm 2.7$ \\
$V_{1}+V_{2}+V_{3}$ & $737.6 \pm 1.0$ \\
\hline
\end{tabular}




\section{Determining Mcles Evolved from the Metal, $n_{D}^{\text {gas }}$}

In order to maximize the amount of deuterium desorbed from the metal deuteride film while limiting thermally induced metal loss or film damage, a rapid thermal ramp method for determining $n_{D}^{g a s}$ was devised. The number of moles of gas evolved from the metal is determined by ramp heating the sample to a nominal $950^{\circ} \mathrm{C}$ at $100^{\circ} \mathrm{C}$ per minute. The sample is placed in the quartz tube, the thermocouple is placed against the outside of the tube and the tube furnace is closed. Next, the manifold is heated to $150^{\circ} \mathrm{C}$ to help remove moisture and adsorbed gases. The system is then evacuated overnight and the pressure is checked to assure system integrity. All valves to the mass spectrometer and additional volumes are closed. The system is ramp heated while the thermocouple temperature $T_{\text {indicated }}$ and pressure $P$ are monitored. As shown in Figure 2, the sample begins outgassing at an indicated temperature of approximately $650^{\circ}$ with the highest rate of outgassing sccurring near $870^{\circ} \mathrm{C}$. Once the system reaches an indicated temperature of $950^{\circ} \mathrm{C}$, the heater is turned off and the quartz tube with the sample is allowed to cool as rajidly as possible to room temperature. Cooling is aided by opening the tube furnace. Following this cooling process, a sample of the gas is introduced into the mass spectrometer to determine the percentages of $\mathrm{D}_{2}$ and $\mathrm{HD}$ present in the gas.

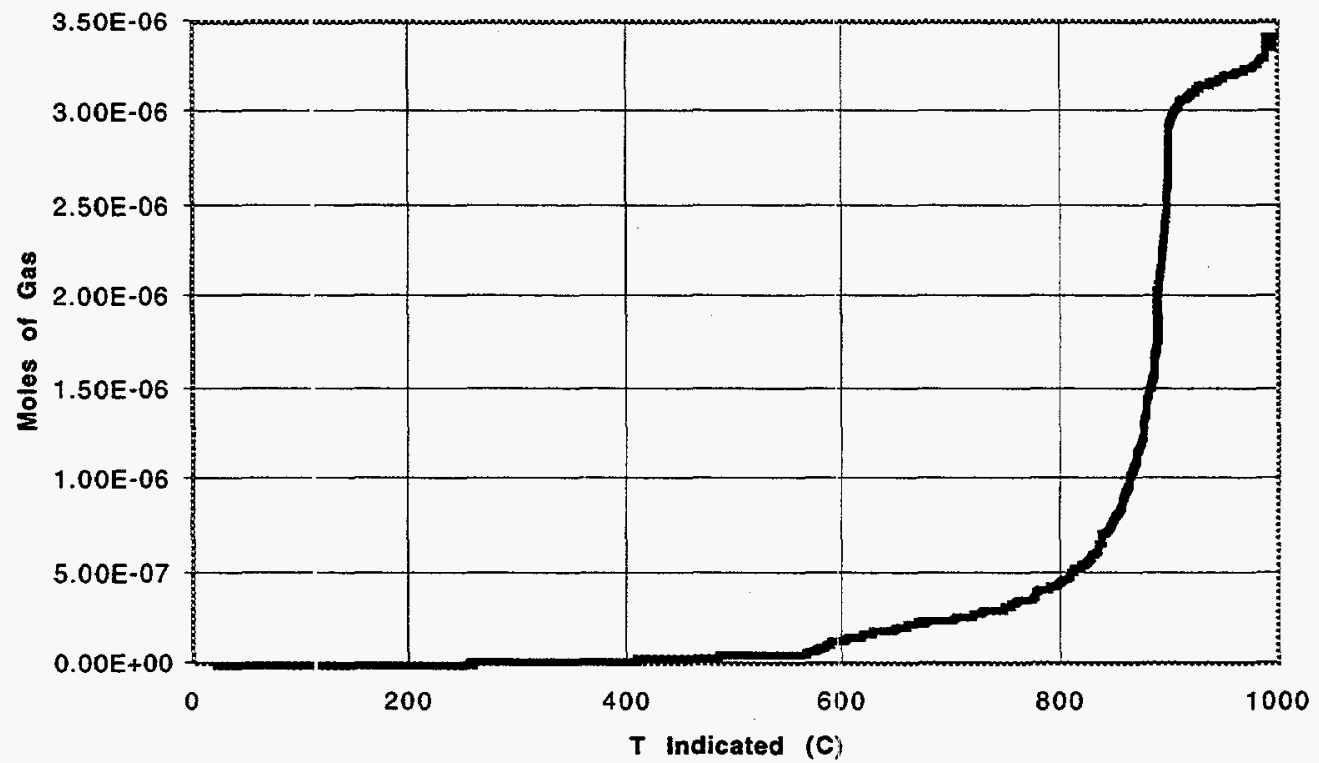

Figure 2. Moles of gas from an erbium deuteride film as a function of indicated temperature.

Since the sample reatsorbs some of the gas during cooling, there was a concern that the percentages of $D_{2}$ and $H D$ determined from a gas sample at room temperature might differ from that present at high temperature following outgassing. During development, mass spectrometer analyses were performed at both high temperature $\left(T_{\text {indicated }}=950^{\circ} \mathrm{C}\right)$ and at room temperiture. This data indicated no significant differences between the compositions of gas samples taken at either temperature. 


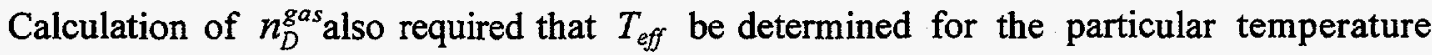
ramp that was used to desorb the deuterium from the film. In the present case, this was accomplished by introducing a known quantity of deuterium into the apparatus at a pressure similar to that which would be generated by an outgassed erbium deuteride sample. This gas sample was then subjected to the previously described temperature program.

Using Equation 5 to calculate the effective temperature, a plot similar to Figure 3 is obtained. The figure shows the effective temperature as a function of time. While the indicated temperature is being ramped, a nearly linear relationship exists between the effective and indicated temperatures.

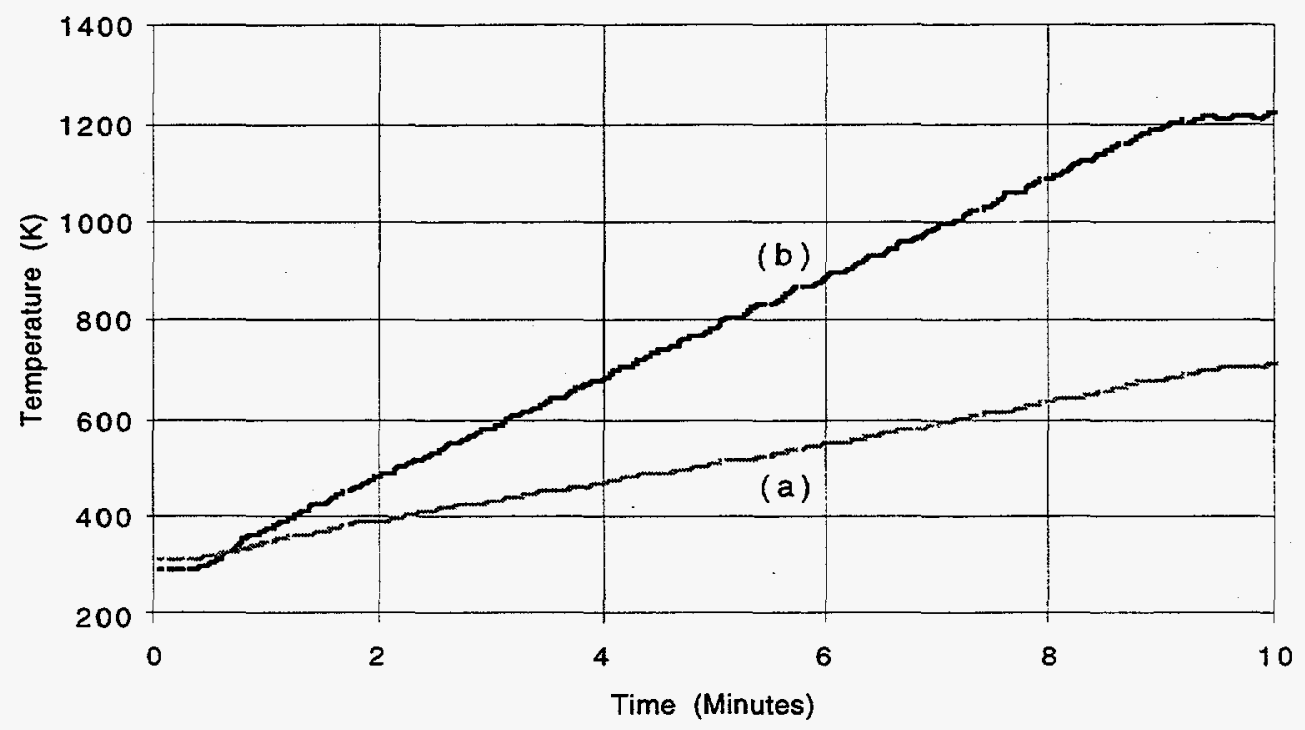

Figure 3. Plot of effective temperature (a) and indicated temperature (b) versus time for the standard deuterium fill for initial ramp.

The reproducibility of this measurement technique was verified by repeating the temperature ramp six times and computing the effective temperature at an indicated temperature of $950^{\circ} \mathrm{C}\left(1223^{\circ} \mathrm{K}\right)$. The results are shown in Table 2 .

Table 2. Effective temperature of the manifold at and indicated temperature of $950^{\circ} \mathrm{C}\left(1223^{\circ} \mathrm{K}\right)$.

\begin{tabular}{c|c} 
Run & Effective Temperature, $\boldsymbol{T}_{\text {eff }}$ \\
\hline 1 & $738^{\circ} \mathrm{K}$ \\
2 & $726^{\circ} \mathrm{K}$ \\
3 & $720^{\circ} \mathrm{K}$ \\
4 & $719^{\circ} \mathrm{K}$ \\
5 & $729^{\circ} \mathrm{K}$ \\
6 & $728^{\circ} \mathrm{K}$ \\
\hline Average/Standard Deviation & $\mathbf{7 2 7}^{\circ} \mathbf{6 . 9}^{\circ} \mathrm{K}$
\end{tabular}


The data show that the calculated effective temperature was repeatable to within a relative standard deviation of $0.9 \%$ for these 6 trials. This means the system reaches, nominally, the same effective temperature each time when the temperature is ramped. Variations in room temperature of $\pm 3^{\circ} \mathrm{C}$ did not seem to have a detectable impact on the measurement. This is probably due to the fact that the operating temperatures are much higher than $23^{\circ} \mathrm{C}$.

\section{Determining Moles Retained in the Metal, $n_{D}^{\text {metal }}$}

The final variable in Equation 2 that must be determined is $n_{D}^{\text {metal }}$, the number of moles of gas retained by the metal film after the initial temperature ramp. Two methods were devised to characterize the outgassing process and determine the moles of retained deuterium. The first method was based on the working hypothesis that the quantity of deuterium retained in the film is determined solely by a gas/solid equilibrium process and that the desorption kinetics play, at best, a minor role. Under this assumption, it would be expected that the amount of retained deuterium would be a function of the deuterium partial pressure in the gas phase above the metal film, and that in the limit of zero equilibrium partial pressure, no deuterium would be retained. This suggests that it should be possible to decrease the deuterium partial pressure in a step-wise fashion, evolve deuterium to reestatlish equilibrium and extrapolate the sum of this incrementally desorbed deuterium to the zero partial pressure limit.

In the present experiment, the pressure in the system was reduced by adding evacuated volumes to the sys:em at specific times. The indicated and calculated effective temperatures are shcwn for the experiment-specific time/temperature profile in Figure 4 , where again, deuterium was used as the calibration gas. The initial ramp to $950^{\circ} \mathrm{C}$ was followed by a hold at that temperature for approximately 33 minutes. At approximately 25 minutes, the valve to $V_{2}$ was opened and the effective temperature (Figure $4, \mathrm{~b})$ dropped as expected ( $V_{2}$ was at room temperature). At approximately 32 minutes, the valve to $V_{3}$ was opened and very little change in the effective temperature was noted. This was probably due to the proportionately small additional volume added.

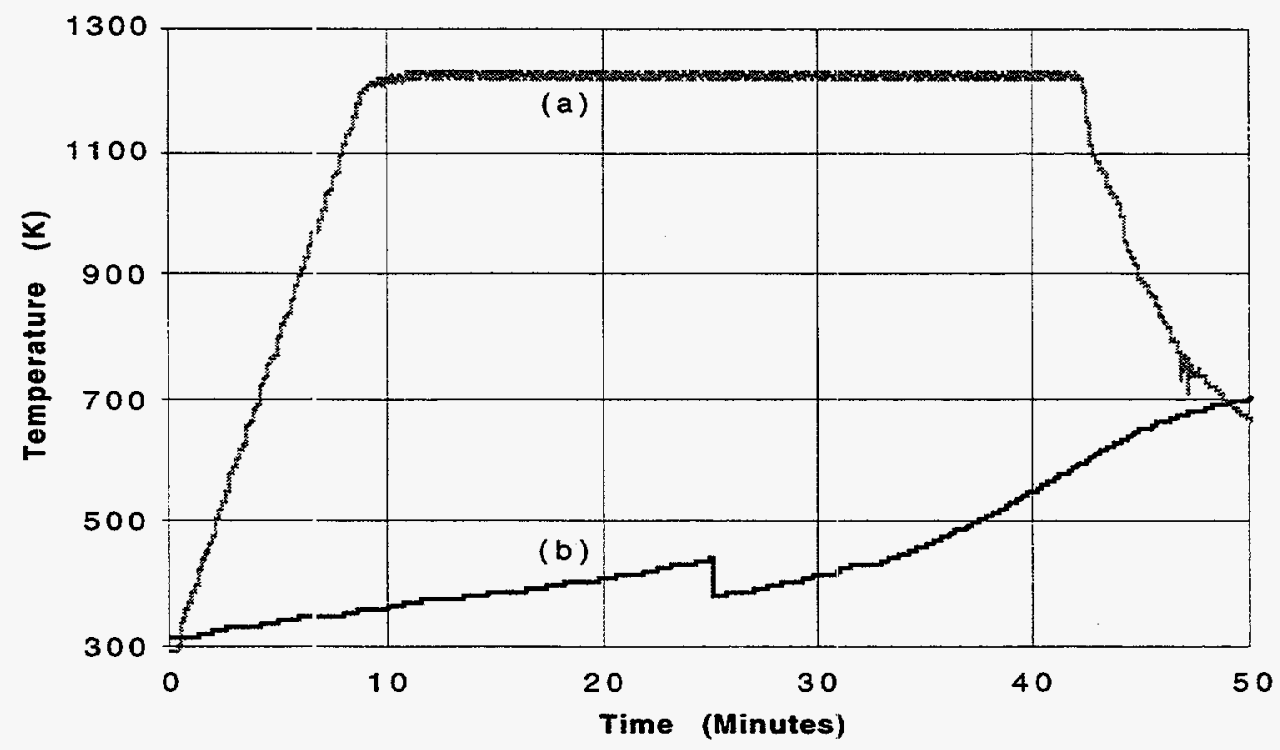

Figure 4. Plot: of indicated temperature (a) and effective temperature (b) versus time for the standard deuterium fill for multiple volume expantion. 
After determining $T_{\text {eff }}$ for this time/temperature/volume profile, the erbium deuteride sample was outgassed using the same profile. The results of this experiment are shown in Figure 5. The majority of deuterium is desorbed in an initial release that occurs at approximately 8 minutes. A small amount of gas continues to be released during the constant temperature hold from 10 minutes to 25 minutes. When the $V_{2}$ valve was opened at 25 minutes, approximately $3 \%$ more gas was released by reducing the system pressure which shifts the equilibrium. Only a few tenths of a percent more gas was released at 32 minutes when $V_{3}$ was opened.

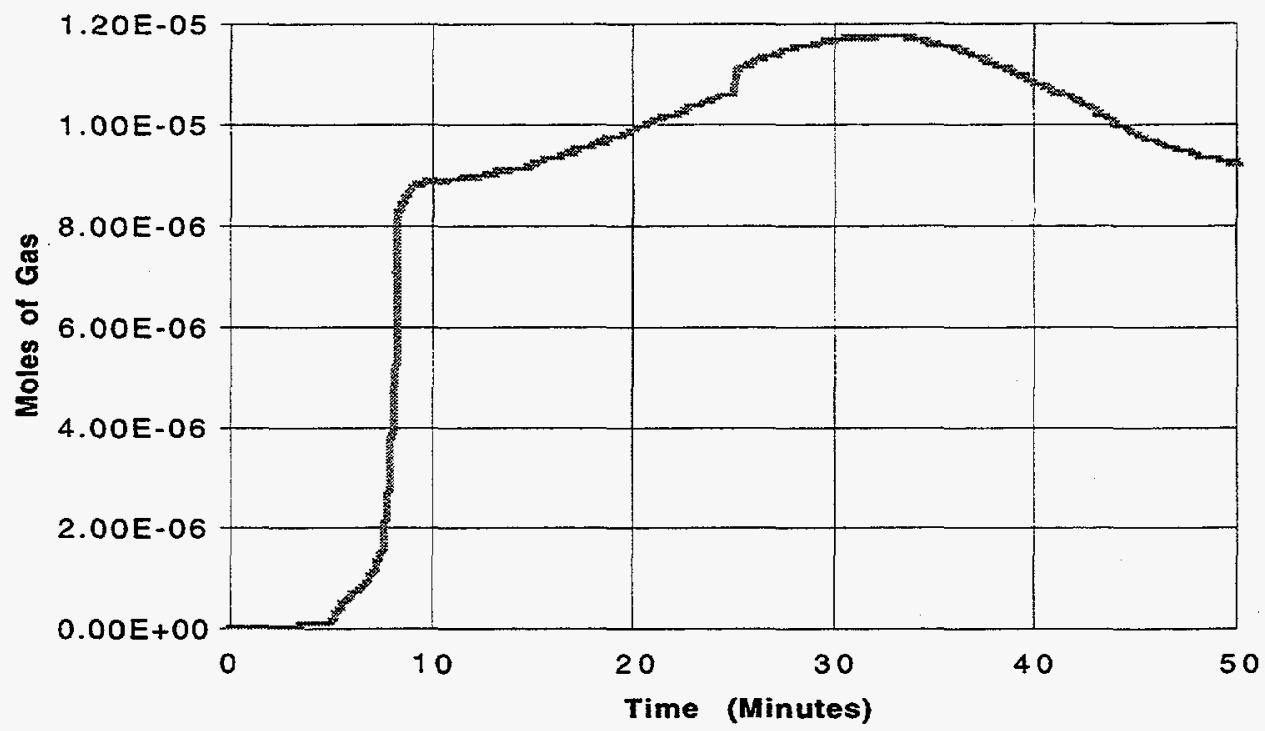

Figure 5. Plot of moles of gas evolved from an erbium deuteride sample versus time.

Although the results of the multiple volume expansion lent a good deal of insight into the desorption process, it also showed that this method was not suitable for making the desired measurement of retained deuterium. Desorption kinetics, for example, were shown to be important. If equilibrium had been quickly reached, the curve of evolved moles of gas as a function of time should have become flat with a slope of zero between volume increments. This was not observed, and gas continued to be evolved. More interestingly, in the region from 32 minutes to 42 minutes, while still maintaining an indicated temperature of $950^{\circ} \mathrm{C}$, a decrease in the total gas moles was observed. This decrease can be explained by the evaporation and redeposition of the erbium ${ }^{13}$ in cooler regions of the manifold. The redeposited erbium can then absorb deuterium which causes the observed decrease. This phenomenon actually has three unfortunate consequences. First, since erbium is acting as both a source and a sink, we can only measure the net change in moles of gas, there is no way to obtain the amount of desorbed deuterium as a separate quantity. Second, as some of the erbium film has evaporated, the subsequent metal analysis will be in error. Finally, and perhaps most importantly, the vacuum system will have been contaminated with a hydrogen getter that will bring into question the results of all future hydrogen analyses.

Taken together, the results of the multiple volume expansion experiment point out the critical need to minimize the time that the metal film is exposed to high temperatures and demonstrate that all of the deuterium can not be desorbed on a time scale that is consistent with maintaining the integrity of the metal film. In order to minimize the 
time the sample sperids at high temperature, the second method, the repeated outgassing method, was developed.

The repeated outgassing experiment consists of rapidly heating the metal hydride sample to a high temperature, cooling to room temperature, evacuating the manifold to remove the deuterium which was not reabsorbed, and then repeating the previous steps until the moles of deuterium pumped away is insignificant. As with the previous experiments, the chosen high temperaiure was nominally $950^{\circ} \mathrm{C}$ since it was above the temperature where the hydride outgasses: rapidly.

The number of molsis of gas pumped away after the $i^{\text {th }}$ outgassing cycle is calculated using the following equation:

$$
n_{i}^{\text {removed }}=\frac{P_{i}}{R} \frac{V_{i}}{T_{i}}\left(2 X_{D_{2}, j}+X_{H D_{i}}\right)
$$

where $P_{i}, V_{i}$, and $T_{i}$ are the pressure, volume, and temperature after equilibration of the entire volume ( $V_{i}=V_{1}$ in this case) to room temperature prior to the $i^{t h}$ removal of gas. Gas mass spectral analyses were performed at each outgassing cycle to determine $X_{D_{2}}$ and $X_{H D}$. The absorbed gas, chemically bound to the erbium, is stable at room temperature so evacisating the volume containing the sample has little or no effect on the deuterium in the metal. The total moles of deuterium in the sample $n_{D}$ are calculated as the sum of the deuterium gas removed during the evacuations and the deuterium found during the final high temperature outgassing $n_{k}^{\text {gas }}$.

$$
n_{D}=n_{k}^{g a s}+\sum_{i=1}^{k-1} n_{i}^{\text {removed }}
$$

Figure 6 shows the cumulative amount of deuterium atoms removed during the pump down process. As can be seen from the figure, after about 7 runs very little deuterium remained in the gas phase (most of the deuterium is reabsorbed by the metal) indicating the absorption/desorrtion of deuterium in the metal film has become nearly reversible. 


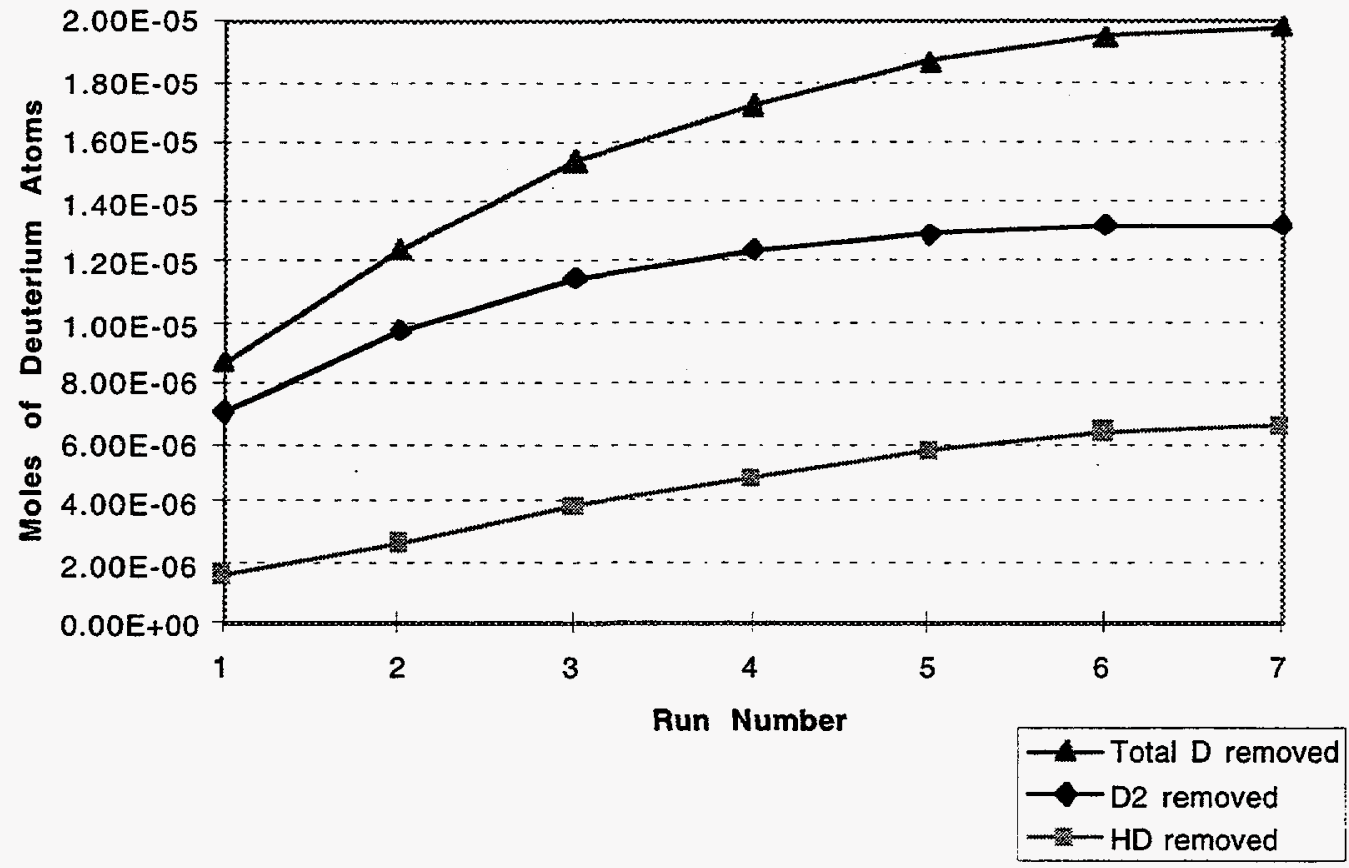

Figure 6. Cumulative amount of deuterium $\left(\mathrm{D}_{2}, \mathrm{HD}\right.$ and Total) removed during the pump down process. After about 7 runs very little deuterium remained in the gas phase after cooling.

Table 3 shows the moles of deuterium removed during each run and in the $k^{\text {th }}$ analysis, and the cumulative total moles of deuterium in the metal.

Table 3. Results of the repeated vacuum removal of deuterium between heating/cooling cycles. The data shows about $10 \%$ of the total moles of gas stored in the metal hydride was not measured (retained in the metal hydride) after the first run

\begin{tabular}{|c|c|c|c|c|}
\hline Run No. & $\begin{array}{c}\text { Cumulative D } \\
\text { removed by vacuum } \\
\text { prior to run } \\
\left(\text { moles } \times \mathbf{1 0}^{-6}\right)\end{array}$ & $\begin{array}{c}\text { Gas phase D from } \\
\text { sample for each } \\
\text { run } \\
\left(\text { moles } \times \mathbf{1 0}^{-6}\right)\end{array}$ & $\begin{array}{c}\text { Cumulative moles } \\
\text { of D atoms } \\
n_{D} \\
\left(\mathbf{m o l e s} \times \mathbf{1 0}^{-6}\right)\end{array}$ & $\begin{array}{c}\text { Amount } \\
\text { left in } \\
\text { Metal at } \\
950^{\circ} \mathrm{C}(\%)\end{array}$ \\
\hline 1 & - & 17.82 & 17.82 & $10.7 \%$ \\
2 & 8.71 & 9.79 & 18.50 & $9.5 \%$ \\
3 & 12.39 & 6.24 & 18.63 & $7.4 \%$ \\
5 & 15.36 & 3.46 & 18.82 & $5.6 \%$ \\
6 & 17.25 & 1.90 & 19.15 & $4.6 \%$ \\
7 & 18.70 & 0.81 & 19.51 & $3.8 \%$ \\
\hline
\end{tabular}

*A small fraction of gas remaining in the disk at $950^{\circ} \mathrm{C}$ was not determined for this last run. 
The data shows tha1, on the first run, approximately $10 \%$ of the deuterium was not released from the metal deuteride at an indicated temperature of $950^{\circ} \mathrm{C}$. Thus, a significant portion of the total deuterium can be easily overlooked by not determining the amount of deuterium remaining in the metal.

To make this method useful for routine analyses, an assumed constant, $K$, can be calculated by dividing the total number of moles of deuterium atoms, $n_{D}$, by the number of moles of deuteriun atoms outgassed on the first run, $n_{i}^{\text {gas }}$ (or equivalently, $n_{D}^{g a s}$ in Eq. 2). Therefore, the total number of moles of $D$ can be determined by outgassing the sample once and multiplying the result by $K$.

$$
K=\frac{n_{D}}{n_{1}^{g a:}} \quad \therefore \quad n_{D}=K \bullet n_{1}^{g a s}
$$

\section{Results}

\section{Deuterium to Eirbium Ratio}

Metal analysis data rvas combined with the gas analysis data to determine the deuterium to erbium ratio (Equation 1) in Table 4. The results for several samples indicate that a nearly stoichiometriv ratio of 2:1 (D:Er) was obtained in each case.

Table 4. Sum mary of results obtained for the ratio of deuterium to erbium for a series of sam ples.

\begin{tabular}{|l|c|c|c|}
\hline Sample II & Moles D & Moles Er & Ratio (D/Er) \\
\hline $\mathrm{Er} / \mathrm{D}_{2} \# 163$ & $1.85 \mathrm{E}-05$ & $9.34 \mathrm{E}-06$ & 1.98 \\
$\mathrm{Er} / \mathrm{D}_{2} \# 164$ & $2.08 \mathrm{E}-05$ & $1.04 \mathrm{E}-05$ & 2.00 \\
$\mathrm{Er} / \mathrm{D} 2 \# 165$ & $1.86 \mathrm{E}-05$ & $9.38 \mathrm{E}-06$ & 1.99 \\
$\mathrm{Er} / \mathrm{D} 2 \# 166$ & $2.04 \mathrm{E}-05$ & $1.03 \mathrm{E}-05$ & 1.98 \\
$\mathrm{Er} / \mathrm{D} 2 \# 167^{*}$ & $1.97 \mathrm{E}-05$ & $9.66 \mathrm{E}-06$ & 2.04 \\
\hline
\end{tabular}

*metal and gas a ialysis performed on sister samples

\section{Conclusion}

Accurate analyses o: deuterium in erbium deuteride films can be made using a rapid ramp outgassing technique. The method is based on high temperature desorption of deuterium from the film with quantitation of the gaseous deuterium being accomplished through the application of the principles underlying the ideal gas law. It was also shown that a significant fraction of the total deuterium is retained in the film under the experimental conditions employed in this study, and a method was presented to account for this retained deuterium. A key result that enabled the use of gas law calculations to quantitate the deuterium, even in the case of a non-isothermal, non-steady-state measurement system, is the demonstrated ability to calibrate the effective temperature of the system for a particular time/temperature profile by subjecting a known quantity of a nonreactive gas to the dentical profile. 
During the course of this investigation, it was shown that both desorption kinetics and gas/solid equilibria influence the deuterium measurement process. As the effects of both of these factors can be varied by changing experimental conditions, temperature ramp rates and sample chamber volumes, for example, the specific results obtained here are applicable solely to the specific apparatus used to make these measurements. The methodology, however, should be generally applicable and should allow other users to perform a thorough evaluation and calibration of their own systems. Finally, the critical importance of minimizing time that the metal film is exposed to high temperature was demonstrated. The effects of such exposure times must be a major consideration in designing any similar high temperature measurement technique. 


\section{References}

${ }^{1}$ W. M. Muller, J.J?. Blackledge, and G.C. Libowitz, eds., Metal Hydrides, Academic Press, London and New York (1968)

${ }^{2}$ Gust Bambakidis, Metal Hydrides, Plenum Press, New York (1981)

${ }^{3}$ M. A. Pick, "The Kinetics of Hydrogen Absorption-Desorption by Metals", Proceedings of a NATO Advanced Study Institute on Metal Hydrides, June 17-27, 1980 in Rhodes, Greece.

${ }^{4}$ J. F. Lennard-Jones, Trans. Faraday Soc., 28:333 (1932)

${ }^{5}$ R. W. Sullivan and C. E. Lundin, "The Erbium-Hydrogen-Deuterium System", DRI Report No. 2379, Denver Research Institute, Denver, CO, 1967.

${ }^{6}$ G. C. Libowitz, Solid State Chemistry of Binary Metal Hydrides, Benjamin Press, New York, 1965.

${ }^{7}$ R. W. Kondrat and R. G. Coors, "Direct Analysis of Mixtures by Mass Spectrometry", Anal. Chem., Vol 50, 1978

${ }^{8}$ L. C. Beavis and C. J. Miglionico, "Structural Behavior of Metal Tritide Films", J. Less Common Metals, V. 29, 1972.

${ }^{9}$ F. W. McLafferty, Interpretation of Mass Spectra, Benjamine Press, 1966

${ }^{10}$ T. K. Mehrhoff and J. O. Humphries, "Analysis of Hydrogen Isotopes in Thin Films", G.E. Technical Information Series, GEPP-215, April, 1976.

${ }^{11}$ P. Chastagner, "Advanced Mass Spectrometers for Hydrogen Isotope Analyses", E. I. duPont, Savanah Fiver Labs, Akin, SC, DPST-84-398, March, 1984.

${ }^{12}$ W. M. Jones, "Thermodynamic Functions of Tritium Hydride. The Dissociation of Tritium Hydride, Equilibrium among Hydrogen Isotope Molecules", J. Chem. Phys., Vol 17, No 11, Nov. 194.9.

${ }^{13}$ B. Tamanian, "Netal Loss on Degassing Erbium Hydride", General Electric Neutron Devices Department Internal Report, CHM-75-131, Largo, Florida, March, 1975.

${ }^{14}$ S. M. Thornberg, J. Vac. Sci. Technol., A6 (4), Jul/Aug 1988, pp. 2522-2527. 